\title{
Exploring the relationship among issues on awareness in practicing waste minimization (Malaysia)
}

\begin{abstract}
This study is carried out to identify the level of awareness associated with waste minimization practices and industrial solid waste. It focuses on the issues of dack of awareness and informationô as preventive factors in waste minimization practices by industries in Malaysia. About 30 industries were randomly sampled from the industrial area using a structured questionnaire, and employs severity index and correlation analysis for data analysis. The correlation analysis is used to identify the relationship between issues in this research. Results revealed that the lack of accurate or sufficient knowledge of waste minimization practices is a serious barrier in waste minimization practices among the industries given the severity index value of $64 \%$. However, the results also show a statistical significant relationship on the lack of accurate or sufficient knowledge and untrained personnel $(r=0.75, p<0.01)$, absence of experts $(r=0.66, p<0.01)$ and limited technical information $(\mathrm{r}=0.61, \mathrm{p}<0.01)$.
\end{abstract}

Keyword: Waste minimization; Industrial waste; Barriers; Information and awareness 